\title{
CARACTERIZAÇÃO FLORÍSTICA E ESTRUTURAL DE UMA FLORESTA OMBRÓFILA DENSA ALTOMONTANA NA SERRA DO CAPIVARI, CAMPINA GRANDE DO SUL, PARANÁ
}

\author{
Renann de Silos Vieira ${ }^{1}$, Christopher Thomas Blum², Carlos Vellozo Roderjan ${ }^{2}$ \\ ${ }^{1}$ Biólogo, mestrando em Engenharia Florestal, UFPR, Curitiba, PR, Brasil - renann.vieira @ufpr.br \\ ${ }^{2}$ Eng. Florestal, Dr., Depto. de Ciências Florestais, UFPR, Curitiba, PR, Brasil - ctblum@ufpr.br; roderjan@ufpr.br \\ Recebido para publicação: 30/09/2013 - Aceito para publicação: 01/04/2014
}

\begin{abstract}
Resumo
Encontrada somente no alto das montanhas da Serra do Mar, a Floresta Ombrófila Densa Altomontana é condicionada por situações ambientais muito singulares, que lhe conferem estrutura e florística exclusivas. O objetivo deste estudo foi caracterizar a composição florística e estrutural de um trecho de Floresta Altomontana na Serra do Capivari, Campina Grande do Sul. Em 20 parcelas de $50 \mathrm{~m}^{2}$, foram analisadas todas as árvores com perímetro à altura do peito $\geq 10 \mathrm{~cm}$. Foram registrados 574 indivíduos, de 24 espécies e 15 famílias. A família mais rica foi Myrtaceae (5), seguida por Melastomataceae e Lauraceae. A floresta estudada apresentou diversidade relativamente baixa $\left(\mathrm{H}^{\prime}=2,58\right.$ nats.ind $\left.^{-1}\right)$ e alta densidade (5.740 ind.ha $\left.{ }^{-1}\right)$, havendo predomínio de árvores finas, que formam um único estrato arbóreo de aproximadamente cinco metros de altura. Presente em todas as parcelas, Ilex microdonta Reissek apresentou a maior importância estrutural na comunidade, com densidade de 1.160 ind.ha ${ }^{-1}$ e dominância de $10,54 \mathrm{~m}^{2} \cdot \mathrm{ha}^{-1}$. Pôde-se confirmar a característica de baixa diversidade da formação Altomontana, composta por famílias de dispersão universal e alta densidade de indivíduos, mas com estrutura dominada por poucas espécies. A baixa estatura e ausência de indivíduos emergentes configura um padrão fisionômico-estrutural inerente a essa formação, decorrente de condicionantes muito restritivas.

Palavras-chave: Floresta nebular de altitude; Serra do Mar; Mata Atlântica; fitossociologia.
\end{abstract}

\begin{abstract}
Floristic and struct/ural characterization of an Upper Montane Atlantic Forest in the Capivari mountain range, Campina Grande do Sul, Parana. Found only in the highest portions of the Serra do Mar mountain range, the Upper Montane Atlantic Forest is conditioned to unique environmental situations that result in exclusive physiognomy. This research aimed to characterize floristic and structural composition of this forest type in the Capivari mountain range, Campina Grande do Sul. 20 plots of $50 \mathrm{~m}^{2}$ were implemented to analyze all individuals with perimeter at breast height $\geq 10 \mathrm{~cm}$. It was registered 574 individuals of 24 species and 15 families. The richest family was Myrtaceae (5 species), followed by Melastomataceae and Lauraceae. The forest presented low diversity $\left(\mathrm{H}^{\prime}=2.58\right.$ nats.ind $\left.{ }^{-1}\right)$ and high density $\left(5,740\right.$ ind.ha $\left.^{-1}\right)$, mainly composed of thin trees and forming an upper stratum of approximately five meters. Ilex microdonta Reissek, registered in all plots, is the most important species in this community, with density of 1,160 ind.ha ${ }^{-1}$ and dominance of $10.54 \mathrm{~m}^{2}$.ha $\mathrm{a}^{-1}$. It was possible to confirm the feature of low species diversity in the Upper Montane forest, composed by families of universal dispersion and high individuals density, but with structure dominated by few species. The low height and the absence of emergent trees endorse a physiognomic-structural standard of this forest that is result of restrictive environmental conditions.
\end{abstract}

Keywords: Montane cloud forest; Serra do Mar mountain range; Atlantic forest; phytosociology.

\section{INTRODUÇÃO}

A porção de Floresta Atlântica encontrada no alto das montanhas da Serra do Mar do Paraná, geralmente entre 1.200 e 1.800 metros de altitude, é coberta quase diariamente por nuvens orográficas, causadas pela ascensão dos ventos quentes oceânicos que esfriam e se condensam nas altitudes elevadas 
(FALKENBERG; VOLTOLINI, 1995; RODERJAN et al., 2002; SCHEER et al., 2011). Tal característica é responsável pelas diferentes denominações dadas a essa formação, entre as quais se destacam: "Mata de Neblina" (MAACK, 1968), "Mata ou Floresta Nebular" (BIGARELLA, 1978; FALKENBERG; VOLTOLINI, 1995) e Floresta Ombrófila Densa Altomontana (VELOSO et al., 1991).

Diferentemente das exuberantes formações florestais localizadas em altitudes inferiores, a formação altomontana é composta por árvores de pequeno porte, que formam apenas um estrato arbóreo, com altura entre 3,5 e $8 \mathrm{~m}$. Suas folhas apresentam tamanho reduzido, ocorrendo a predominância de epífitas avasculares (HUECK, 1972; RODERJAN, 1994; DOUMENGE et al., 1995; PORTES et al., 2001; KOEHLER et al., 2002; FALKENBERG, 2003; SCHEER et al., 2011).

Fatores ambientais, como solos pouco desenvolvidos (Neossolos Litólicos e Organossolos Fólicos), nebulosidade frequente, exposição a ventos fortes, temperaturas baixas e a consequente diminuição nas taxas de decomposição e mineralização da serapilheira, são determinantes para a constituição estrutural e florística das florestas altomontanas (LACERDA, 2001; PORTES et al., 2001).

Segundo Falkenberg e Voltolini (1995), a precipitação média no ambiente altomontano é geralmente maior que $1.500 \mathrm{~mm}$, sendo que outros autores relatam valores entre $2.000 \mathrm{~mm}$ (RODERJAN, 1994; ROCHA, 1999) e 3.000 mm anuais (MAACK, 1968; IAPAR, 2000). Para Hamilton et al. (1995), as florestas nebulares tropicais ocorrem, em escala global, dentro de um largo intervalo de regime de precipitação (500-10.000 mm/ano). Essa variação significativa ocorre de acordo com a posição altitudinal e a orientação da faixa de vegetação nas montanhas.

Dessa forma, na medida em que se eleva a altitude, modificam-se as condições de clima, solo e geomorfologia, as quais definem a estrutura e a fisionomia da formação vegetacional, em que cada faixa altitudinal possui a sua própria composição de espécies, determinando um tipo florestal específico (RODERJAN, 1994; KOEHLER et al., 2002; MONTAGNINI; JORDAN, 2005). Para Falkenberg e Voltolini (1995), as florestas nebulares não formam apenas um tipo homogêneo de vegetação, mas um grupo de comunidades com florísticas relativamente similares, praticamente ignoradas pelos botânicos até a década de 1970. Com base nesse contexto, o presente trabalho teve como objetivo caracterizar a florística e a estrutura de um trecho de Floresta Ombrófila Densa Altomontana em uma subserra do Complexo da Serra do Mar, no estado do Paraná, assim como efetuar comparações de composição florística entre a área estudada e outras áreas similares no estado.

\section{MATERIAL E MÉTODOS}

A serra do Capivari está localizada no município de Campina Grande do Sul, PR, entre as coordenadas $25^{\circ} 08^{\prime} \mathrm{S}$ e $48^{\circ} 49^{\prime} \mathrm{N}$ (Figura 1), cujo ponto culminante atinge aproximadamente 1.657 metros de altitude. Limita-se ao norte com a região montanhosa do vale do Ribeira, a oeste com o planalto da bacia do rio Capivari, a leste com a planície do rio Cachoeira e ao sul com a serra do Ibitiraquire (MAACK, 1968). Encontra-se assentada sobre maciços graníticos de idade paleozoica, classificados como Granito Graciosa, que apresentam direção NE e fazem contatos tectônicos com rochas do domínio Curitiba a oeste, e do domínio Paranaguá a leste (BRASIL, 2004). Segundo Scheer et al. (2011), os solos nos ambientes altomontanos são pouco desenvolvidos, extremamente ácidos, com altos teores de carbono, baixa saturação por bases e alta saturação por alumínio trocável. Ainda segundo os autores, o desenvolvimento de florestas nesses ambientes é promovido pelo espessamento dos horizontes minerais e o adelgaçamento dos horizontes orgânicos.

De acordo com a classificação climática de Koeppen, o clima da região é do tipo $\mathrm{Cfb}$, subtropical sempre úmido, com verões frescos, geadas frequentes e sem estação seca definida (INSTITUTO AGRONÔMICO DO PARANÁ, 1994). Na Serra do Mar, esse tipo climático tem sua ocorrência restrita a níveis altitudinais superiores aos 800 m s.n.m. (MAACK, 1968; RODERJAN, 1994; BLUM et al., 2011).

A distribuição das parcelas se deu de forma aleatória, dentro da faixa altitudinal de 1.500 a $1.600 \mathrm{~m}$ s.n.m., em locais onde a floresta exibia fisionomia característica da formação altomontana (árvores baixas formando um único estrato, com troncos retorcidos e abundância de epífitas avasculares). Ao todo, 20 parcelas de $5 \times 10 \mathrm{~m}$ foram demarcadas, dentro das quais foram analisados e coletados todos os indivíduos com perímetro à altura do peito $(\mathrm{PAP})$ igual ou superior a $10 \mathrm{~cm}(\mathrm{DAP} \geq 3,2 \mathrm{~cm})$. 
A determinação das espécies foi realizada com o uso de chaves de identificação, comparação com material dos herbários Museu Botânico Municipal (MBM) e Escola de Florestas Curitiba (EFC) e consultas a especialistas. Utilizou-se a classificação taxonômica proposta pelo Angiosperm Phylogeny Group (APG III, 2009) para o reconhecimento das famílias de angiospermas. O material de referência foi incorporado ao acervo do Herbário EFC e as duplicatas doadas ao MBM e ao Herbário do Departamento de Botânica da Universidade Federal do Paraná (UPCB).
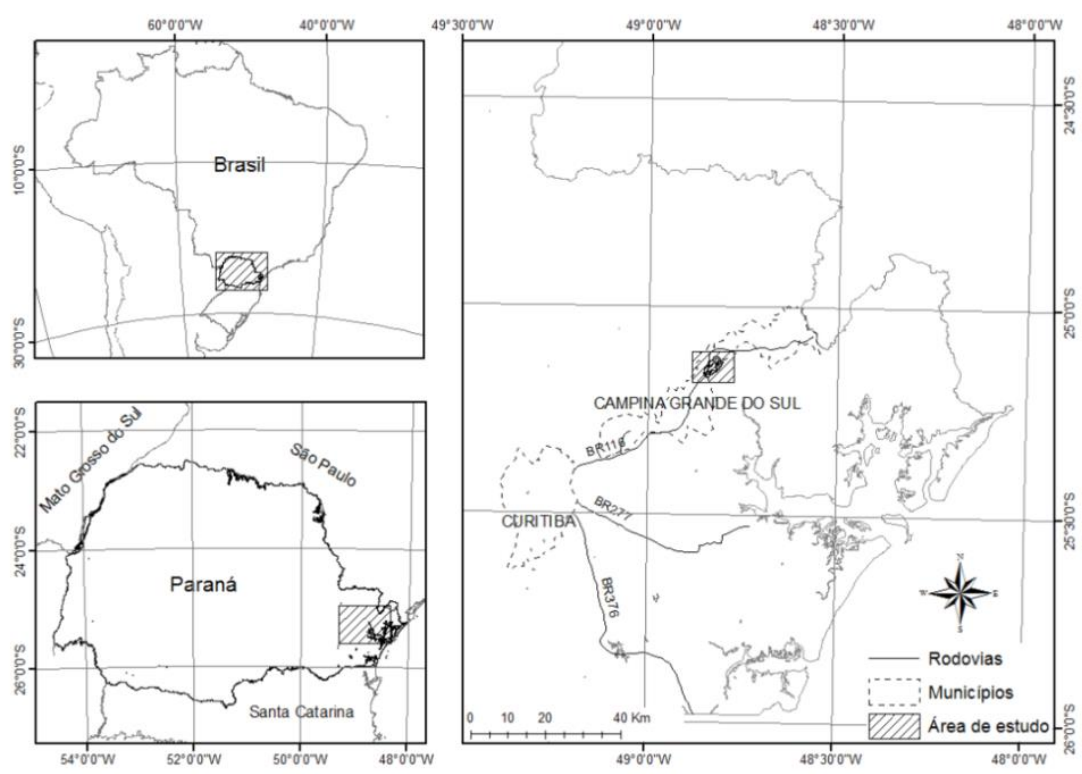

Figura 1. Localização da área de estudo, serra do Capivari, no município de Campina Grande do Sul, PR. Figure 1. Focused area location, in the Capivari mountain range, Campina Grande do Sul municipality, PR.

Para controle, todas as informações obtidas em campo foram anotadas em uma ficha, contendo a identificação, o PAP e o valor estimado da altura total. Os dados coletados foram processados usando-se o programa FITOPAC I (SHEPHERD, 1995), para cálculo dos parâmetros fitossociológicos, conforme descrito por Daubenmire (1968) e Mueller-Dombois e Ellenberg (1974). Foram calculados os índices de diversidade de Shannon (H') e de Equabilidade de Pielou (J'), conforme Magurran (1988).

Para verificação da similaridade florística do componente arbóreo da serra do Capivari com outros nove sítios de florestas altomontanas paranaenses (RODERJAN, 1994; ROCHA, 1999; PORTES et al., 2001; KOEHLER et al., 2002; SCHEER et al., 2011), foram calculados os índices de similaridade de Sörensen, cujo cálculo considerou somente as determinações em nível de espécie, após uma revisão das sinonímias botânicas. Buscando-se analisar a semelhança florístico-estrutural desses nove sítios, foi realizada a análise de agrupamento com base na porcentagem de importância das espécies. Tal análise foi realizada através do programa STATISTICA 7, sendo o agrupamento construído pelo método de Ward (variância mínima), com a utilização da distância euclidiana quadrática como medida métrica (VALENTIN, 2000). Para definição dos distintos grupos formados, foi considerado o número de ramos interceptados pela linha fenon, que parte da distância euclidiana média (metade da maior distância), paralelamente ao eixo horizontal, conforme Johnson e Wichern (1982).

\section{RESULTADOS E DISCUSSÃO}

Foram registrados 574 indivíduos arbóreos, distribuídos por 24 espécies e 15 famílias (Tabela 2), o que resultou em um índice de diversidade de Shannon $\left(\mathrm{H}^{\prime}\right)$ de 2,58 nats.ind ${ }^{-1}$ e equabilidade (J) de 0,802. Assim como observado em outras serras paranaenses (RODERJAN, 1994; ROCHA, 1999; PORTES et al., 2001; KOEHLER et al., 2002; SCHEER et al., 2011), os baixos valores de diversidade são atribuídos ao aumento do grau de adversidade ambiental decorrente da elevação da altitude, posto 
que, sob condições pedoclimáticas críticas, apenas algumas espécies conseguem se estabelecer (PORTES et al., 2001). Comparando a estrutura de quatro serras paranaenses, Scheer et al. (2011) verificaram que o menor valor de diversidade foi encontrado na serra do Ibitiraquire $\left(\mathrm{H}^{\prime}=2,50\right.$ nats.ind $\left.{ }^{-1}\right)$, local com as maiores altitudes do estado.

O reduzido número de espécies arbóreas encontrado na maioria dos estudos em florestas altomontanas se deve, segundo Scheer et al. (2011), à tendência de haver predomínio estrutural de poucas espécies por unidade de área, não sendo rara a ocorrência de apenas quatro ou cinco representando mais de 50\% da comunidade (RODERJAN, 1994; ROCHA, 1999; PORTES et al., 2001), aspecto também observado no presente estudo.

Entre as variáveis estruturais analisadas, a maior homogeneidade foi verificada para o diâmetro médio (Tabela 1), com baixos valores de coeficiente de variação e erro amostral relativo. De forma análoga, para a variável altura média, a amostragem também se mostrou satisfatória, com erro amostral relativo inferior a $10 \%$, limite comumente aceito para inventários de florestas plantadas, no nível de $95 \%$ de probabilidade (SANQUETTA et al., 2009). Para todas as variáveis, com exceção da área basal, o número de parcelas de $50 \mathrm{~m}^{2}$ indicadas pelo cálculo de suficiência amostral foi inferior ao número de parcelas implantadas em campo, demonstrando que, de modo geral, a área total amostrada foi satisfatória.

Tabela 1. Estatísticas descritivas para as variáveis estruturais de um trecho de Floresta Ombrófila Densa Altomontana na serra do Capivari, PR. Legenda: Hmed = altura média; Dmed = diâmetro médio.

Table 1. Descriptive statistics for the structural variables of a stretch of an Upper Montane Atlantic Forest in the Capivari mountain range, PR. Legend: Hmed = average height; Dmed = average diameter.

\begin{tabular}{lcccc}
\hline Estatística & $\begin{array}{c}\text { Hmed } \\
(\mathbf{m})\end{array}$ & $\begin{array}{c}\text { Dmed } \\
(\mathbf{c m})\end{array}$ & $\begin{array}{c}\text { Área basal } \\
\left(\mathbf{m}^{\mathbf{2}} \mathbf{. h a} \mathbf{1}^{-1}\right)\end{array}$ & $\begin{array}{c}\text { Densidade } \\
\left(\mathbf{i n d . h a}^{-\mathbf{1}}\right)\end{array}$ \\
\hline Média & $3,9 \pm 0,3$ & $7,9 \pm 0,5$ & $0,19 \pm 0,03$ & $5.740 \pm 331$ \\
Coeficiente de variação & $16,4 \%$ & $13,1 \%$ & $33,7 \%$ & $12,3 \%$ \\
Erro amostral relativo* & $7,7 \%$ & $6,1 \%$ & $15,8 \%$ & $17,7 \%$ \\
\hline
\end{tabular}

* a $95 \%$ de probabilidade de confiança.

As variáveis densidade e área basal apresentaram valores de erros amostrais relativos ligeiramente acima de $10 \%$, mas aceitáveis dentro de um contexto de razoável variabilidade estrutural das florestas nativas. De qualquer modo, evidencia-se que um aumento na área amostral poderia contribuir com resultados mais precisos, principalmente para área basal. A grande variação dessa variável se deve principalmente à ocorrência de alguns indivíduos com diâmetros acima da média e também pela existência de clareiras no interior da floresta, muitas vezes dominadas pela espécie herbácea Aechmea ornata Baker (Bromeliaceae). A existência de clareiras pode estar relacionada a eventos de deslocamentos de massa que, por sua vez, são atribuídos às elevadas declividades aliadas à ocorrência de solos pouco espessos e geralmente em contato lítico.

No presente estudo, as seis espécies mais importantes representaram $63,9 \%$ da porcentagem de importância (PI) (Tabela 2), fato considerado comum em hábitats sujeitos a condições extremas, em que poucas espécies representam praticamente toda a comunidade (SCARANO, 2002). As espécies com maior PI foram: Ilex microdonta, Symplocos incrassata, Siphoneugena reitzii, Weinmannia humilis, Laplacea fructicosa e Ilex chamaedryfolia.

Assim como verificado na serra da Baitaca por Roderjan (1994), a espécie Ilex microdonta ocorreu em todas as parcelas, representando mais de $20 \%$ do total de indivíduos registrados. Trata-se da espécie de maior importância nessa comunidade, apresentando os maiores valores de densidade e dominância. A presença marcante de I. microdonta nas montanhas paranaenses foi também registrada nos estudos realizados por Rocha (1999) no Pico do Marumbi, e por Koehler et al. (2002) nos morros Mãe Catira e Torre do Vigia. Já no estudo de Scheer et al. (2011) - realizado nas serras da Prata, da Igreja, do Gigante e Ibitiraquire, essa espécie não foi registrada como a $1^{\mathrm{a}}$ colocada em importância, porém sempre esteve entre o grupo das mais importantes em cada uma das áreas de estudo, juntamente com Siphoneugena reitzii.

Apesar de ocorrer em outras serras paranaenses, S. incrassata se destacou por ter apresentado valores estruturais superiores aos registrados em outros estudos (RODERJAN, 1994; ROCHA, 1999; KOEHLER et al., 2002; SCHEER et al., 2011), assumindo o segundo lugar em termos de importância 
estrutural na serra do Capivari. Aranha Filho (2011) descreve essa espécie como rara no Brasil e sugere sua inclusão na listagem de Aranha Filho et al. (2009). Com o terceiro lugar em importância, S. reitzii apresentou valores de densidade e frequência superiores aos de $S$. incrassata, porém com valores de diâmetro e altura inferiores, totalizando menor dominância.

Tabela 2. Parâmetros fitossociológicos das espécies arbóreas amostradas em $1.000 \mathrm{~m}^{2}$ de Floresta Ombrófila Densa Altomontana na serra do Capivari, PR. Legenda: DA: densidade absoluta; DR: densidade relativa; DoA: dominância absoluta; DoR: dominância relativa; FA: frequência absoluta; PI: porcentagem de importância.

Table 2. Structural parameters of tree species sampled in $1,000 \mathrm{~m}^{2}$ of an Upper Montane Atlantic Forest in the Capivari mountain range, PR. Legend: DA: absolute density; DR: relative density; DoA: absolute dominance; DoR: relative dominance; FA: absolute frequency; PI: percentage of importance.

\begin{tabular}{|c|c|c|c|c|c|c|c|}
\hline Famílias & Espécies & $\begin{array}{c}\text { DA } \\
\left.\text { (ind.ha }^{-1}\right)\end{array}$ & $\begin{array}{l}\text { DR } \\
(\%) \\
\end{array}$ & $\begin{array}{c}\text { DoA } \\
\left(\mathbf{m}^{2} \cdot \mathbf{h a}^{-1}\right)\end{array}$ & $\begin{array}{l}\text { DoR } \\
(\%) \\
\end{array}$ & $\begin{array}{l}\text { FA } \\
(\%)\end{array}$ & $\begin{array}{c}\text { PI } \\
(\%) \\
\end{array}$ \\
\hline AQUIFOLIACEAE & Ilex microdonta Reissek & 1160 & 20,2 & 10,54 & 28,0 & 100 & 19,3 \\
\hline SYMPLOCACEAE & Symplocos incrassata Aranha & 620 & 10,8 & 5,56 & 14,8 & 90 & 11,4 \\
\hline MYRTACEAE & Siphoneugena reitzii D.Legrand & 760 & 13,2 & 3,93 & 10,4 & 95 & 11,0 \\
\hline CUNONIACEAE & Weinmannia humilis Engl. & 350 & 6,1 & 3,96 & 10,5 & 70 & 7,80 \\
\hline THEACEAE & Laplacea fructicosa (Schrad.) Kobuski & 380 & 6,6 & 3,01 & 8,0 & 65 & 6,97 \\
\hline AQUIFOLIACEAE & Ilex chamaedryfolia Reissek & 410 & 7,1 & 1,73 & 4,6 & 90 & 6,81 \\
\hline LAURACEAE & Ocotea porosa (Nees \& Mart.) Barroso & 350 & 6,1 & 1,26 & 3,3 & 70 & 5,40 \\
\hline MYRTACEAE & $\begin{array}{l}\text { Myrceugenia seriatoramosa (Kiaersk.) D.Legrand \& } \\
\text { Kausel }\end{array}$ & 320 & 5,6 & 1,23 & 3,3 & 65 & 5,04 \\
\hline BIGNONIACEAE & Handroanthus catarinensis (A.H.Gentry) S.Grose & 260 & 4,5 & 1,05 & 2,8 & 55 & 4,21 \\
\hline LAURACEAE & Ocotea tristis (Nees \& Mart.) Mez & 280 & 4,9 & 0,61 & 1,7 & 55 & 3,94 \\
\hline WINTERACEAE & Drimys angustifolia Miers & 100 & 1,7 & 1,35 & 3,6 & 35 & 2,91 \\
\hline CLETHRACEAE & Clethra uleana Sleumer & 100 & 1,7 & 0,62 & 1,7 & 30 & 2,10 \\
\hline MYRTACEAE & Myrcia hartwegiana (O.Berg) Kiaersk. & 70 & 1,2 & 0,10 & 0,3 & 30 & 1,46 \\
\hline MYRTACEAE & Myrcia guianensis (Aubl.) DC. & 50 & 0,9 & 0,20 & 0,5 & 25 & 1,27 \\
\hline MELASTOMATACEAE & Miconia lymanii Wurdack & 30 & 0,5 & 0,18 & 0,5 & 15 & 0,82 \\
\hline PRIMULACEAE & Myrsine altomontana M.F.Freitas \& Kin.-Gouv. & 30 & 0,5 & 0,04 & 0,1 & 15 & 0,69 \\
\hline CARDIOPTERIDACEAE & Citronella engleriana (Loes.) R.A.Howard & 30 & 0,5 & 0,20 & 0,5 & 10 & 0,67 \\
\hline LAURACEAE & Persea willdenovii Kosterm. & 20 & 0,3 & 0,24 & 0,6 & 10 & 0,65 \\
\hline RHAMNACEAE & Rhamnus sphaerosperma $\mathrm{Sw}$. & 40 & 0,7 & 0,08 & 0,2 & 10 & 0,62 \\
\hline MYRTACEAE & Blepharocalyx salicifolius (Kunth) O.Berg & 10 & 0,2 & 0,03 & 0,08 & 5 & 0,25 \\
\hline PROTEACEAE & Roupala consimilis Mez ex Taub. & 10 & 0,2 & 0,03 & 0,07 & 5 & 0,24 \\
\hline MELASTOMATACEAE & Tibouchina reitzii Brade & 10 & 0,2 & 0,03 & 0,07 & 5 & 0,24 \\
\hline MELASTOMATACEAE & Leandra quinquedentata (DC.) Cogn. & 10 & 0,2 & 0,01 & 0,04 & 5 & 0,23 \\
\hline ERICACEAE & Gaultheria serrata var. organensis (Meisn.) Luteyn & 10 & 0,2 & 0,01 & 0,03 & 5 & 0,23 \\
\hline Indivíduos mortos & & 330 & 5,75 & 1,59 & 4,24 & 75 & 5,74 \\
\hline TOTAL & & 5740 & 100,0 & 37,59 & 100,0 & - & 100,0 \\
\hline
\end{tabular}

Outra espécie importante na comunidade foi Ilex chamaedryfolia, que apresentou uma grande quantidade de indivíduos registrados e ocorreu em $90 \%$ das unidades amostrais.

A presença das espécies Ocotea tristis, Miconia lymanii, Gaultheria serrata var. organensis e Leandra quinquedentata, registradas até o momento apenas nos estudos florísticos (qualitativos) de Scheer e Mocochinski (2009), associada à grande importância fitossociológica de $S$. incrassata, confere à serra do Capivari um padrão florístico-estrutural único entre as serras do Complexo da Serra do Mar no Paraná.

Segundo Freitas e Kinoshita (2005), Silva et al. (2010) e Aranha Filho (2011), as espécies Myrsine altomontana, Gaultheria serrata var. organensis e Symplocos incrassata podem ser consideradas como restritas aos patamares altitudinais superiores aos $1.200 \mathrm{~m}$ s.n.m. no Paraná. Desse modo, podem figurar como endêmicas da floresta Altomontana, demonstrando sua grande relevância para a conservação. Ainda nesse âmbito, Handroanthus catarinensis e Ocotea porosa também merecem 
destaque, por serem citadas em relações de espécies raras ou ameaçadas (FUNDAÇÃO BIODIVERSITAS, 2005; QUINET et al., 2013).

As famílias que apresentaram as maiores PI foram Aquifoliaceae, Myrtaceae, Symplocaceae, Lauraceae e Cunoniaceae, sendo que apenas as duas primeiras representam mais de $40 \%$ da estrutura florestal (Tabela 3). Com relação à quantidade de indivíduos registrados, as três famílias de maiores PI representaram $60 \%$ da comunidade estudada. A família Aquifoliaceae, representada por apenas um gênero e duas espécies, apresentou o maior número de indivíduos, sendo $75 \%$ referentes apenas à espécie I. microdonta. Em outros estudos realizados na Serra do Mar paranaense, essas cinco famílias também foram registradas como as mais representativas da Floresta Ombrófila Densa Altomontana (RODERJAN, 1994; ROCHA, 1999; PORTES et al., 2001; KOEHLER et al., 2002; SCHEER et al., 2011). As famílias Theaceae, Winteraceae, Primulaceae, Melastomataceae e Proteaceae, registradas no presente estudo com menor expressividade, são destacadas por Hueck (1972) e Roderjan (1994) como igualmente importantes na fisionomia da formação altomontana.

Tabela 3. Número de espécies, de indivíduos e porcentagem de importância das principais famílias encontradas em um trecho de Floresta Ombrófila Densa Altomontana na serra do Capivari, PR.

Table 3 Number of species, individuals and percentage of importance of the most important families found in an Upper Montane Atlantic Forest of the Capivari mountain range, PR.

\begin{tabular}{lccccc}
\hline Famílias & $\mathbf{N}^{\mathbf{0}}$ de sp. & \% de sp. & $\mathbf{N}^{\mathbf{0}}$ de ind. & \% de ind. & PI (\%) \\
\hline AQUIFOLIACEAE & 2 & 8,3 & 157 & 27,3 & 24,3 \\
MYRTACEAE & 5 & 20,8 & 121 & 21,1 & 16,2 \\
SYMPLOCACEAE & 1 & 4,2 & 62 & 10,8 & 12,4 \\
LAURACEAE & 3 & 12,5 & 65 & 11,3 & 9,3 \\
CUNONIACEAE & 1 & 4,2 & 35 & 6,1 & 8,6 \\
Outras 10 famílias & 12 & 50 & 101 & 17,6 & 29,1 \\
\hline
\end{tabular}

A família Myrtaceae foi a mais representativa em termos de riqueza, com cinco espécies e quatro gêneros, seguida de Lauraceae e Melastomataceae, ambas com três espécies cada. As demais famílias registradas foram representadas por apenas uma espécie.

Considerando valores estruturais gerais da comunidade, uma característica comum às florestas altomontanas é a alta densidade de indivíduos arbóreos, aspecto que pode ser utilizado como indicador dessa fisionomia de vegetação, a qual geralmente apresenta valores superiores a 4.000 ind.ha $^{-1}$ (KOEHLER et al., 2002). Para o trecho estudado, foi obtida uma densidade de 5.740 ind.ha $^{-1}$, superior aos valores encontrados na maioria dos estudos realizados na Floresta Ombrófila Densa Altomontana no Paraná, que utilizaram os mesmos critérios de inclusão adotados neste trabalho, nos quais a densidade variou de 3.533 ind.ha $^{-1}$ a 4.830 ind.ha $^{-1}$ (RODERJAN, 1994; ROCHA, 1999; PORTES et al., 2001; KOEHLER et al., 2002; SCHEER et al., 2011). Única exceção é a serra do Gigante, onde foi registrada uma densidade de 6.288 ind./ha (SCHEER et al., 2011).

A área basal da floresta foi de $37,59 \mathrm{~m}^{2} . \mathrm{ha}^{-1}$, valor muito próximo dos registrados por Rocha (1999) $\left(35,24 \mathrm{~m}^{2} \cdot \mathrm{ha}^{-1}\right)$, Scheer et al. (2011) $\left(40,3 \mathrm{~m}^{2} . \mathrm{ha}^{-1}\right)$ e Portes et al. (2001) $\left(41,87 \mathrm{~m}^{2} . \mathrm{ha}^{-1}\right)$, respectivamente, nas serras do Marumbi, do Ibitiraquire e da Baitaca. Em outras serras do Paraná, registraram-se valores relativamente mais baixos. Dos quatro locais estudados por Koehler et al. (2002), os três situados em menores altitudes (abaixo de $1.400 \mathrm{~m}$ s.n.m.) apresentaram área basal inferior a $30 \mathrm{~m}^{2}$.ha $\mathrm{h}^{-1}$. Isso também foi verificado em três áreas estudadas por Scheer et al. (2011), as serras da Prata, da Igreja e do Gigante $\left(29,4 \mathrm{~m}^{2} \cdot \mathrm{ha}^{-1}, 30,5 \mathrm{~m}^{2} \cdot \mathrm{ha}^{-1}\right.$ e $29,6 \mathrm{~m}^{2}$.ha ${ }^{-1}$, respectivamente). É possível que essas diferenças estejam mais relacionadas às peculiaridades ambientais das áreas analisadas, uma vez que a tendência esperada seria de aumento da área basal com a redução da altitude, aspecto comprovado por Roderjan (1994) em um gradiente de 1.135 a 1.400 m de Floresta Ombrófila Densa.

O diâmetro médio da comunidade foi de $7,9 \mathrm{~cm}$ e a grande maioria $(72,8 \%)$ dos indivíduos se distribuiu dentro da faixa de menor diâmetro (Figura 2A). O maior valor encontrado foi de $38,8 \mathrm{~cm}$, pertencente à espécie I. microdonta. 

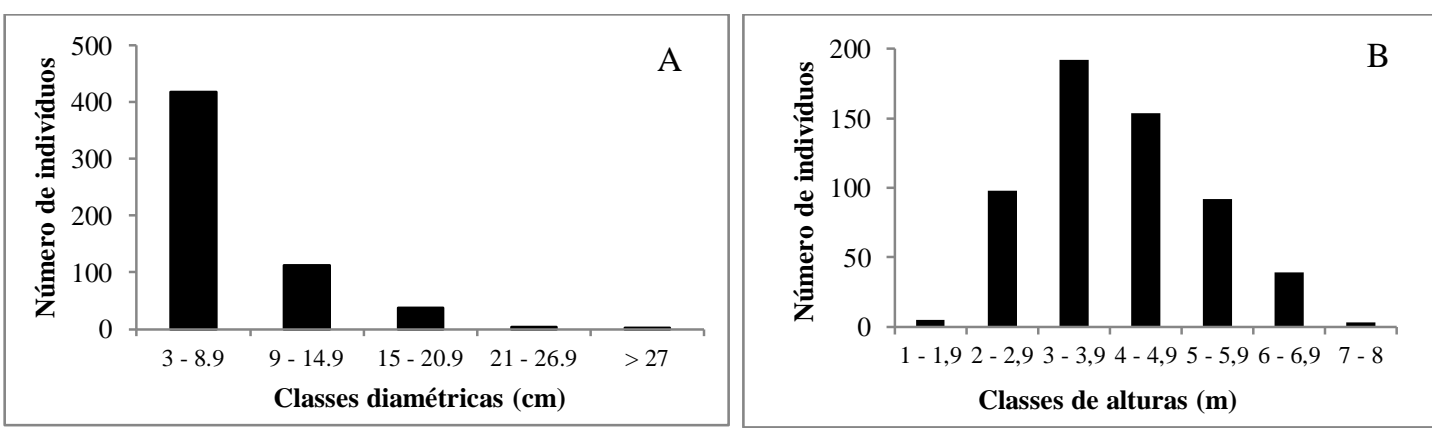

Figura 2 Distribuição dos indivíduos em classes diamétricas (A) e de altura (B), de um trecho de Floresta Ombrófila Densa Altomontana na serra do Capivari, PR.

Figure 2. Distribution of individuals according to diameter (A) and height (B) classes of an Upper Montane Atlantic Forest in the Capivari mountain range, PR.

A altura média da comunidade arbórea foi de 3,9 metros e a maioria dos indivíduos se enquadrou dentro da faixa de 3,0 a 4,9 m (Figura 2B), em concordância com o que foi observado em outros estudos na formação altomontana (RODERJAN, 1994; DOUMENGE et al., 1995; PORTES et al., 2001; KOEHLER et al., 2002; FALKENBERG, 2003). Os maiores valores de altura registrados foram 7,5 m e 7,1 m, respectivamente, de I. microdonta e H. catarinensis (Figura 3).

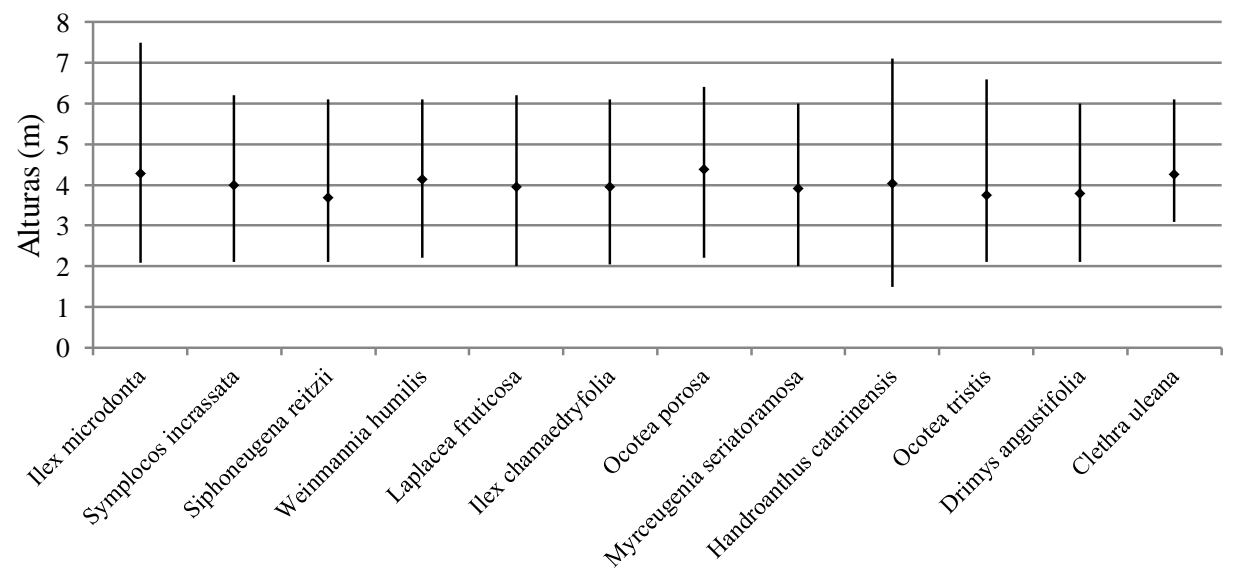

Figura 3. Alturas mínimas, médias e máximas das principais espécies encontradas em um trecho de Floresta Ombrófila Densa Altomontana na serra do Capivari, PR.

Figure 3. Minimum, average and maximum height values of the most important species found in an Upper Montane Atlantic Forest, Capivari mountain range, PR.

A ausência de árvores emergentes é uma característica muito marcante nas florestas altomontanas, onde mesmo as árvores com maiores diâmetros não ultrapassam a altura do dossel, formando um estrato único e compacto. Para Koehler et al. (2002), essa característica é resposta adaptativa às rigorosas condicionantes ambientais, com destaque para os ventos fortes e as limitações do espaço disponível para sustentação radicial. Segundo esses mesmos autores, outro fator importante a se considerar são os movimentos de massas do solo, causados pela declividade do terreno, forçando até mesmo as árvores com maiores alturas a se inclinarem no sentido da vertente.

Analisando os índices de similaridade de Sörensen entre a área de estudo e outros sítios de Floresta Ombrófila Densa Altomontana no Paraná (Tabela 4), foi constatada uma elevada similaridade florística entre a serra do Capivari e as áreas estudadas na serra do Marumbi (ROCHA, 1999) e no sítio 1 da serra da Baitaca (RODERJAN, 1994), com as quais apresentou, respectivamente, 16 e 15 espécies em comum. A serra da Graciosa (KOEHLER et al., 2002) também apresentou considerável similaridade com 
a área de estudo. Verificou-se, portanto, que as formações altomontanas das quatro serras supracitadas formam um conjunto com grande semelhança no âmbito da composição florística.

Tabela 4. Similaridade florística (índice de Sörensen) entre a área de estudo e outros nove sítios de florestas altomontanas paranaenses: serra da Baitaca, sítio 1 (RODERJAN, 1994), sítio 2 (PORTES et al., 2001); serra do Marumbi (ROCHA, 1999); serras da Graciosa, do Salto e do Araçatuba (KOEHLER et al., 2002); serras do Ibitiraquire, da Prata e da Igreja (SCHEER et al., 2011).

Table 4. Floristic similarity (Sörensen index) for the study area and nine other sites of Upper Montane Atlantic Forest in Parana: Baitaca mountain range, site 1 (RODERJAN, 1994), site 2 (PORTES et al., 2001); Marumbi mountain range (ROCHA, 1999); Graciosa, Salto and Araçatuba mountain ranges (KOEHLER et al., 2002); Ibitiraquire, Prata and Igreja mountain ranges (SCHEER et al., 2011).

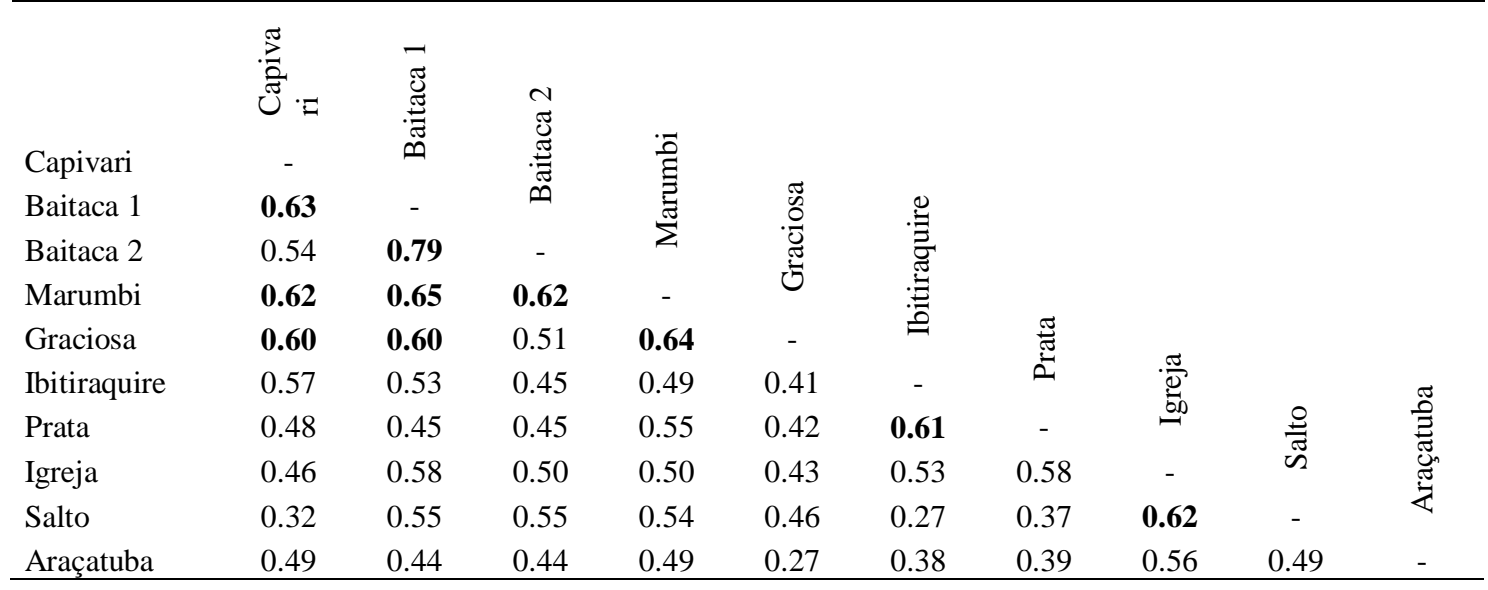

O local que apresentou a menor similaridade florística com a serra do Capivari foi a serra do Salto (KOEHLER et al., 2002), sendo verificadas apenas sete espécies em comum entre as duas áreas.

No dendrograma resultante da análise de agrupamento para os mesmos sítios analisados (Figura 4), evidencia-se a formação de quatro grupos, sendo dois deles compostos por apenas uma serra cada, Araçatuba e Salto. A serra do Araçatuba foi a que apresentou as maiores diferenças estruturais entre os sítios comparados, sendo também o local com o menor número de espécies registradas (18). Tanto na serra do Araçatuba quanto na serra do Salto, verificou-se a ausência de algumas espécies típicas das florestas altomontanas, como S. reitzii e I. chamaedrifolia que, além de estarem presentes em todos os outros sítios analisados, geralmente enquadram-se entre as dez de maior importância estrutural nessas áreas. Também para a serra do Araçatuba se verificou a ocorrência de espécies típicas de patamares altitudinais inferiores, como Prunus brasiliensis e Ilex paraguariensis, o que foi atribuído por Koehler et al. (2002) à localização da comunidade analisada em fundo de vale, protegida, dessa forma, dos extremos ambientais.

Um terceiro grupo é composto pelos estudos realizados na serra da Baitaca (RODERJAN, 1994; PORTES et al., 2001) e na serra da Graciosa. Tais serras compartilham da presença expressiva de $I$. microdonta, que apresentou porcentagens de importância próximas ou superiores a $30 \%$, aspecto que certamente influiu substancialmente em seu agrupamento.

O quarto grupo é formado por um número maior de sítios, incluindo as serras do Capivari (área de estudo), Marumbi, Igreja, Prata e Ibitiraquire. A alta similaridade florístico-estrutural verificada para as duas últimas é coerente, já que, entre as dez espécies com maior expressão estrutural em cada serra, nove são comuns a ambas. Junto dessas serras, ficou agrupada a serra da Igreja, que, assim como as outras, apresentou como espécies mais importantes Ilex microdonta, Siphoneugena reitzii e Drimys angustifolia. Saliente-se que a elevada similaridade estrutural entre essas três serras é coerente com os índices de similaridade florística apresentados entre elas (Tabela 4).

Apesar de terem sido igualmente reunidas no quarto grupo, as serras do Capivari e Marumbi formaram um subgrupo separado, em parte devido a sua considerável similaridade florística (Tabela 4), mas também por apresentarem nove espécies comuns dentre as dez de maior importância estrutural em 
cada serra. Sua distinção dentro do grupo se justifica por apresentarem constituição estrutural relativamente singular e, portanto, menos semelhante com as serras da Igreja, Prata e Ibitiraquire. Especificamente para a serra do Capivari, se destaca como fator diferencial a elevada importância estrutural apresentada por $S$. incrassata, característica que não se repete para as outras serras do grupo. De forma análoga, na serra do Marumbi, Ocotea porosa se destacou com a maior porcentagem de importância. Apesar de ter sido registrada também em todos os outros sítios analisados, em nenhum deles apresentou-se como a espécie de maior importância estrutural. É importante ressaltar que a espécie Ocotea porosa ocorrente em florestas altomontanas foi anteriormente considerada como Ocotea catharinensis Mez. (RODERJAN, 1994; ROCHA, 1999; PORTES et al., 2001; KOEHLER et al., 2002), sendo esta de grande semelhança vegetativa, porém de ocorrência restrita aos patamares altitudinais montanos (BROTTO, 2010).

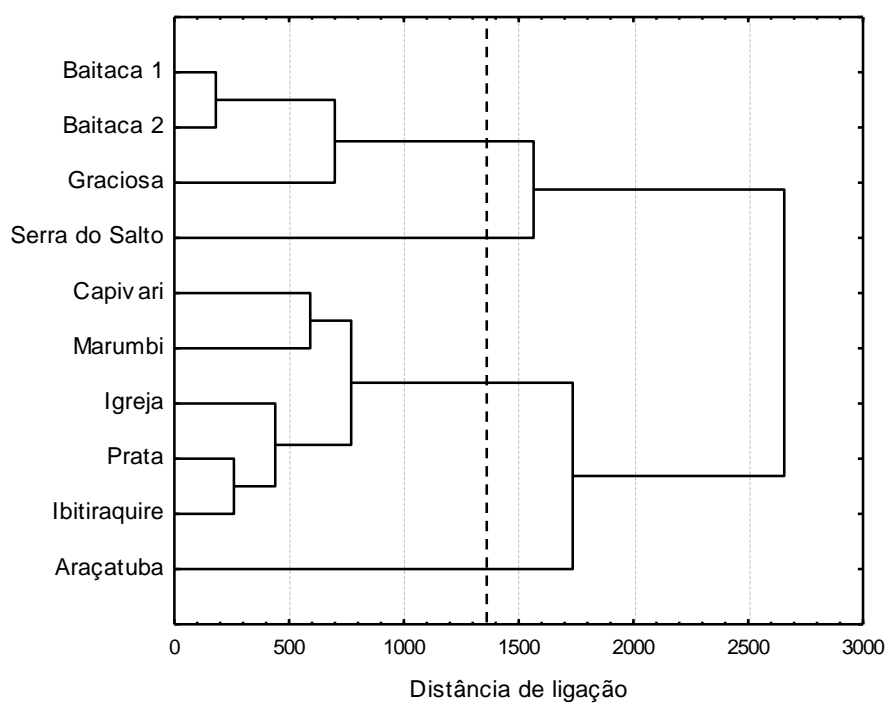

Figura 4. Dendrograma resultante da análise de agrupamento pelo método Ward com a utilização da distância euclidiana quadrática, baseado na porcentagem de importância das espécies arbóreas em diferentes sítios de Floresta Ombrófila Densa Altomontana no Paraná (a linha fenon, que separa os grupos, é representada pelo tracejado).

Figure 4. Dendrogram cluster analysis by Ward method using the squared Euclidean distance, based on the percentage of importance of tree species in different sites of Upper Montane Rain Forest in Parana (the fenon line, that separate the groups, is represented by a dotted line).

\section{CONCLUSÕES}

- Como já constatado em outros estudos em Floresta Ombrófila Densa Altomontana, a riqueza e diversidade florística no trecho estudado foram relativamente baixas, ao passo que a densidade de indivíduos foi bastante elevada. As restrições ambientais existentes em altitudes elevadas, principalmente relacionadas a características pedológicas menos favoráveis, restringem o desenvolvimento dos indivíduos, resultando em uma floresta de baixa estatura e com apenas um estrato arbóreo, com predomínio de fustes finos que raramente ultrapassam sete metros de altura, sendo suas menores dimensões compensadas pela maior densidade de indivíduos.

- Ilex microdonta, Symplocos incrassata e Siphoneugena reitzii foram as espécies que mais se destacaram do ponto de vista estrutural, sendo notável a relevância fitossociológica de $S$. incrassata, aspecto não registrado em outros sítios de formação altomontana no Paraná.

- Entre as famílias botânicas consideradas mais representativas do ponto de vista estrutural, destacaram-se Myrtaceae, Melastomataceae, Lauraceae e Aquifoliaceae.

- A predominância de espécies como I. microdonta e S. reitzii, associada às características estruturais de elevada densidade e baixa estatura dos indivíduos arbóreos, pode ser utilizada como indicativo da ocorrência da Floresta Ombrófila Densa Altomontana no estado do Paraná. 
- A serra do Capivari demonstrou maior similaridade florística com as serras da Baitaca e do Marumbi, apresentando também razoável semelhança fitossociológica com esta última.

- Apesar de relativamente similares de um modo geral, as florestas altomontanas paranaenses apresentam características florístico-estruturais próprias, constatando-se para a serra do Capivari um conjunto de espécies que, embora comum a outras serras, diferencia-se devido à sua composição fitossociológica.

- A conservação das comunidades florestais altomontanas torna-se justificável, seja pela presença de espécies raras ou endêmicas, seja devido à grande importância que essas florestas têm para a estabilidade das encostas na Serra do Mar.

\section{REFERÊNCIAS}

ANGIOSPERM PHYLOGENY GROUP. An update of the Angiosperm Phylogeny Group classification for the orders and families of flowering plants: APG III. Botanical Journal of the Linnean Society, Londres, v. 161, p. 105 - 121, 2009.

ARANHA FILHO, J. L. M.; MARTINS, A. B.; FRITSCH, P. W.; ALMEDA, F. Symplocaceae. In: GIULIETTI, A. M.; RAPINI, A.; ANDRADE, M. J. G.; QUEIROZ, L. P.; SILVA, J. M. C. Plantas raras do Brasil. Conservação Internacional, Belo Horizonte, 2009. p. 380 - 381.

ARANHA FILHO, J. L. M. Revisão taxonômica das espécies sul-americanas de Symplocos Jacq. seção Hopea (L.) A. DC. (Symplocaceae). 328 f. Tese (Doutorado em Biologia Vegetal) - Instituto de Biologia, Universidade Estadual de Campinas, Campinas, 2011.

BIGARELlA, J. J. (Coord.) A Serra do mar e a porção oriental do estado do Paraná: contribuição à geografia, geologia e ecologia regional. Governo do Estado do Paraná. Curitiba: ADEA, 1978. 248 p.

BLUM, C. T.; RODERJAN, C. V.; GALVÃO, F. O clima e sua influência na distribuição da Floresta Ombrófila Densa na serra da Prata, Morretes, Paraná. Floresta, Curitiba, v. 41, p. 589 - 598, 2011.

BRASIL. Departamento Nacional de Produção Mineral. Plano Diretor de Mineração para a Região Metropolitana de Curitiba. Curitiba: MINEROPAR, 2004.

BROTTO, M. L. Estudo taxonômico do gênero Ocotea Aubl. (Lauraceae) na Floresta Ombrófila Densa no estado do Paraná. Dissertação (Mestrado em Engenharia Florestal). Setor de Ciências Agrárias, Universidade Federal do Paraná, Curitiba, 2010.

DAUBENMIRE, R. Plant communities. New York: Harper \& Row. Pub., 1968. 300 p.

DOUMENGE, C.; GILMOR, D.; PEREZ, M. R.; BLOCKHUS, J. Tropical Montane Cloud Forests: conservation status and management issues. In: HAMILTON, L. S.; JUVIK, J. O.; SCATENA, F. N. Tropical montane cloud forests. New York, 1995. p. 24 - 37.

FALKENBERG, D. de B.; VOlTOLINI, J. C. The Montane Cloud Forest in Southern Brazil. In: HAMILTON, L. S.; JUVIK, J. O.; SCATENA, F. N. Tropical montane cloud forests. New York, 1995. p. $138-149$.

FALKENBERG, D. de B. Matinhas nebulares e vegetação rupícula dos Aparados da Serra Geral (SC/RG), sul do Brasil. 558 f. Tese (Doutorado em Biologia). Instituto de Biologia, Universidade Estadual de Campinas, Campinas, 2003.

FREITAS, M. F.; KINOSHITA, L. S. Novas espécies de Myrsine L. (Myrsinaceae) para o Brasil. Rodriguésia, Rio de Janeiro, v. 56, n. 87, p. 67 - 72, 2005.

FUNDAÇÃO BIODIVERSITAS. Lista da flora brasileira ameaçada de extinção. 2005. Disponível em: 〈http://www.biodiversitas.org.br/florabr/lista_florabr.pdf>. Acesso em: 30/06/2011.

HAMILTON, L. S.; JUVIK, J. O.; SCATENA, F. N. The Puerto Rico Tropical Cloud Forest Symposium: introduction and Workshop Synthesis. Ecological Studies, New York, v. 110, p. 1 - 23, 1995. 
HUECK, K. As florestas da América do Sul: ecologia, composição e importância econômica. São Paulo: Polígono, 1972. 161 p.

INSTITUTO AGRONÔMICO DO PARANÁ. Cartas climáticas do estado do Paraná. IAPAR. Documento, 18. Londrina, PR, Brasil. 49 p. 1994.

JOHNSON, R. A.; WICHERN, D. W. Applied Multivariate Statistical Analysis. Madison: Prentice Hall International, 1982. $607 \mathrm{p}$.

KOEHLER, A.; GALVÃO, F.; LONGHI, S. J. Floresta Ombrófila Densa Altomontana: Aspectos florísticos e estruturais de diferentes trechos na serra do Mar, PR. Ciência Florestal, Santa Maria, v. 12, n. 2 , p. $27-39,2002$.

LACERDA, M. S. Composição florística e estrutura da comunidade arbórea num gradiente altitudinal de Mata Atlântica. 123 f. Tese (Doutorado em Biologia) - Instituto de Biologia, Universidade Estadual de Campinas, Campinas, 2001.

MAACK, R. Geografia física do estado do Paraná. Curitiba: M. Roesner, 1968. 350 p.

MAGURRAN, A. E. Ecological diversity and its measurement. Princeton, Princeton University Press, 1988.

MONTAGNINI, F.; JORDAN, C. F. Tropical Forest Ecology: the basis for Conservation and Management. New York, Springer Berlin-Heidelberg, 2005. 295 p.

MUELLER-DOMBOIS, D. \& ELLENBERG, H. Aims and methods of vegetation ecology. New York: John Wiley \& Sons, 1974. $547 \mathrm{p}$.

PORTES, M. C. G. de O.; GALVÃO, F.; KOEHLER, A. Caracterização florística e estrutural de uma Floresta Ombrófila Densa Altomontana do morro do Anhangava, Quatro Barras, PR. Floresta, Curitiba, v. 31, n. 1/2, p. 9 - 18, 2001.

QUINET, A.; KUTSCHENKO, D. C.; BARROS, F. S. M.; MORAES, M. M. V.; FERNANDEZ, E. P.; MESSINA, T. Lauraceae. In: MARTINELLI, G.; MORAES, M. A. Livro vermelho da flora do Brasil. Rio de Janeiro, 2013. p. 601.

ROCHA, M. do R. L. Caracterização fitossociológica e pedológica de uma Floresta Ombrófila Densa Altomontana no Parque Estadual Pico do Marumbi, Morretes, PR. 81 f. Dissertação (Mestrado em Engenharia Florestal) - Setor de Ciências Agrárias, Universidade Federal do Paraná, Curitiba, 1999.

RODERJAN, C. V. A Floresta Ombrófila Densa Altomontana do morro do Anhangava, Quatro Barras, PR - Aspectos climáticos, pedológicos e fitossociológicos. $119 \mathrm{f}$. Tese (Doutorado em Engenharia Florestal) - Setor de Ciências Agrárias, Universidade Federal do Paraná, Curitiba, 1994.

RODERJAN, C. V.; GALVÃO, F.; KUNIYOSHI, Y. S.; HATSCHBACH, G. G. As unidades fitogeográficas do estado do Paraná, Brasil. Ciência \& Ambiente, Santa Maria, v. 13, n. 24, p. 75 - 92, 2002.

SANQUETTA, C. R.; WATZLAWICK, L. F.; DALlA CÔRTE, A. P.; FERNANDES, L. A. V.; SIQUEIRA, J. D. P. Inventários florestais: planejamento e execução. 2. ed. Curitiba: Multi-Graphic Gráfica e Editora, 2009. 316 p.

SCARANO, F. R. Structure, function and floristic relationships of plant communities in stressful habitats marginal to the Atlantic Rainforest. Annals of Botany, Oxford, v. 90, p. 517 - 524, 2002.

SCHEER, M. B.; MOCOCHINSKI, A. Y. Florística vascular da Floresta Ombrófila Densa Altomontana de quatro serras no Paraná. Biota Neotropica, São Paulo, v. 9, n. 2, p. 51 - 70, 2009.

SCHEER, M. B.; MOCOCHINSKI, A. Y.; RODERJAN, C. V. Estrutura arbórea da Floresta Ombrófila Densa Altomontana de serras do Sul do Brasill Acta Botânica Brasílica, Feira de Santana, v. 25, n. 4, p. 735 - 750, 2011. 
SHEPHERD, G. J. Fitopac I - versão preliminar. Campinas: UNICAMP, 1995.

SILVA, R. R.; CERVI, A. C.; SANTOS, E. P. Flórula do Morro dos Perdidos, Serra do Araçatuba, Paraná, Brasil: Ericaceae. Acta Biológica Paranaense, Curitiba, v. 39, n. 3-4, p. 87 - 97, 2010.

VALENTIN, J. L. Ecologia numérica: uma introdução à análise multivariada de dados ecológicos. Interciência, Rio de Janeiro, 2000.

VELOSO, H. P.; RANGEL FILHO, A. L. R.; LIMA, J. C. A. Classificação da vegetação brasileira, adaptada a um sistema universal. Rio de Janeiro: IBGE, Departamento de Recursos Naturais e Estudos Ambientais, 1991. 123 p. 